\title{
First observations of SPEAR-induced topside and bottomside sporadic $E$ layer heating observed using the EISCAT Svalbard and SuperDARN radars
}

\author{
L. J. Baddeley, ${ }^{1}$ I. Haggstrøm, ${ }^{2}$ T. K. Yeoman, ${ }^{3}$ and M. Rietveld ${ }^{4}$ \\ Received 16 August 2011; revised 8 November 2011; accepted 8 November 2011; published 12 January 2012.
}

[1] We present the first observations of heater-induced simultaneous topside and bottomside sporadic $E$ layer enhancements at very high latitudes $\left(78.15^{\circ} \mathrm{N}\right)$ using the Space Plasma Exploration by Active Radar (SPEAR) heating facility and the European Incoherent Scatter (EISCAT) Svalbard Radar. During the experiment the SPEAR heating facility was transmitting with $O$-mode polarization in a field-aligned direction with a constant effective radiated power of $\sim 16 \mathrm{MW}$. Results show distinct heater-induced enhancements in both the ion and plasma line spectra. The plasma line enhancements are observed at the SPEAR heater frequency of $4.45 \mathrm{MHz}$. The plasma line observations represent the highest spatial resolution data $(100 \mathrm{~m})$ obtained of such heater-induced enhancements and indicate simultaneous enhancements at both the topside and bottomside of the layer, respectively (located at $\sim 107.5$ and $109 \mathrm{~km}$ altitude, respectively). It is postulated that the results represent evidence of $\mathrm{O}$ - to $Z$-mode conversion of the heater wave occurring at the bottom of the $E$ layer, allowing propagation through the layer resulting in simultaneous topside enhancements. The $Z$-mode enhancements are observed outside the Spitze angle, which is thought to be a result of field-aligned irregularities causing an increase in angular extent of the observations. Additional data from the Super Dual Auroral Radar Network (SuperDARN) HF Finland radar are also shown, which indicate that upon a thinning of the sporadic $E$ layer, the heater beam propagated into the $F$ region, where it induced artificial field-aligned irregularities.

Citation: Baddeley, L. J., I. Haggstrøm, T. K. Yeoman, and M. Rietveld (2012), First observations of SPEAR-induced topside and bottomside sporadic $E$ layer heating observed using the EISCAT Svalbard and SuperDARN radars, J. Geophys. Res., 117, A01307, doi:10.1029/2011JA017079.

\section{Introduction}

[2] Experiments to artificially modify the Earth's ionosphere by means of high-power HF Radio waves have been undertaken since the 1970s [e.g., Carlson and Duncan, 1977]. It is widely accepted that the high-power 'heater' beam can excite a range of plasma instabilities, which in turn cause amplification of electrostatic plasma wave modes.

[3] A heater beam transmitted with an ordinary polarization (O mode) into the ionosphere will be reflected downward at the altitude where the heater frequency, $f_{h}$ equals the electron plasma frequency, $f_{p}$. Different instabilities, as a result of the heater beam interaction with the ionosphere, are then observed at specific altitudes below this height as enhancements in radar backscatter. During transmission of an $\mathrm{O}$-mode heater wave there are two distinguishable types of backscatter observed.

\footnotetext{
${ }^{1}$ University Centre in Svalbard, Longyearbyen, Norway.

${ }^{2}$ EISCAT Scientific Association, Kiruna, Sweden.

${ }^{3}$ Department of Physics and Astronomy, University of Leicester, Leicester, UK.

${ }^{4}$ EISCAT Scientific Association, Tromsø, Norway.

Copyright 2012 by the American Geophysical Union. 0148-0227/12/2011JA017079
}

The first is that of artificially generated field-aligned irregularities (AFAIs). Such irregularities are thought to be generated through the thermal parametric instability (TPI) whereby the heater wave couples to upper hybrid waves at the upper hybrid resonance (UHR) height, which lies a few kilometers below the $O$-mode wave reflection height [Robinson, 1989, and references therein]. The irregularities extend for several tens of kilometers along the geomagnetic field line and are thus most easily observable using coherent backscatter radar, which relies on the beam being orthogonal to the geomagnetic field. There have been observations made of such irregularities by the Super Dual Auroral Network (SuperDARN radars) [Greenwald et al., 1995], which have been generated by several ionospheric heating facilities including European Incoherent Scatter (EISCAT) [Baddeley et al., 2002], HAARP [Hughes et al., 2004], and Space Plasma Exploration by Active Radar (SPEAR) [Robinson et al., 2006]. The AFAIs are far more intense and coherent than naturally occurring field-aligned irregularities (FAIs) [Yeoman et al., 2006] resulting in higher observed backscatter power and lower observed spectral width.

[4] The second type of heater-induced backscatter is observable by incoherent scatter radars and can be seen to extend both parallel to and a few degrees offset from the 
geomagnetic field direction. The scatter results from the excitation of both low-frequency ion acoustic waves and highfrequency Langmuir waves at the $O$-mode reflection height. Two main interaction mechanisms have been suggested for these enhancements which are observable by incoherent scatter radar. The first is the Purely Growing mode (PGM) instability [Fejer and Leer, 1972], also called the modulation instability [Goldman et al., 1995], and the Oscillating Two Stream Instability (OTSI) [e.g., Nishikawa, 1968]. In this interaction the heater wave decays into two oppositely directed high-frequency Langmuir waves and a low-frequency nonpropagating ion acoustic wave. The second is called the Parametric Decay Instability (PDI) [e.g., Fejer, 1979] in which the heater wave decays into two oppositely directed highfrequency Langmuir waves and ion acoustic waves. Both interactions are observable as enhancements in both the ion and plasma line spectra measured by Incoherent Scatter Radars. Enhancements in both ion and plasma line spectra have been generated using all the heating facilities noted above (see review by Leyser and Wong [2009]).

[5] The excitation of the PGM and PDI occurs just below the $O$-mode reflection height. In comparison, the generation of AFAIs through the TPI occurs at a lower altitude, at the UHR height (which typically lies a few kilometers below the $O$-mode reflection height). It has been shown [e.g., Robinson, 2002] that the absorption of the heater beam at the upper hybrid height, resulting in the generation of AFAIs, will thus prevent the heater beam reaching the altitude with sufficient amplitude required for generation of the PGM and PDI. While this seems to be true for ionospheric heaters located at lower latitudes, it has been shown [e.g., Robinson et al., 2006] that this is not always the case at SPEAR, with observations made of enhancements in both coherent and incoherent scatter occurring concurrently. The relatively few observations of this phenomenon to date has meant that a suitable understanding of the physical processes is still lacking.

[6] In addition to $O$-mode propagation, other phenomena can be observed when heating around the so-called Spitze angle [e.g., Budden, 1980], $\theta_{c}$, which is defined as

$$
\sin \left(\theta_{c}\right)=\sin (\alpha) \sqrt{\frac{Y}{1+Y}}
$$

where $Y=f_{e} / f_{h}$.

[7] Here, $f_{e}$ is the electron gyrofrequency and $\alpha$ is the magnetic dip angle. It is possible for an $O$-mode wave launched into the ionosphere at this angle, $\theta_{c}$, to undergo mode conversion into a $Z$-mode wave. The propagation of this $Z$-mode will then depend on, both the heater and plasma frequency.

[8] At SPEAR, the magnetic field dip angle is, $\alpha \sim 8^{\circ}$, and electron gyro frequency, $f_{e} \sim 1.4 \mathrm{MHz}$. For the $E$ region this results in a Spitze angle, $\theta_{c} \sim 3^{\circ}-4^{\circ}$. The SPEAR beam is $14^{\circ} \times 21^{\circ}$ wide, thus when the beam is pointing in a fieldaligned direction ionospheric heating can occur at the Spitze angle. If the conditions are also such that the ionospheric peak plasma density (in this case in the $E$ region, $f_{o} E$ ) satisfies the condition

$$
f_{h}<f_{o} E<f_{h}+\frac{f_{e}}{2},
$$

then the $Z$-mode wave will propagate through to the topside of the region where a similar interaction will occur with the heater beam exciting electrostatic plasma wave modes.

[9] Observations of $O$ - to $Z$-mode conversion at lower latitudes using the EISCAT UHF and VHF radars in combination with the heater at Tromsø $\left(69.58^{\circ} \mathrm{N}, 19.23^{\circ} \mathrm{E}\right.$, magnetic dip angle $\sim 13^{\circ}, \theta_{c} \sim 5^{\circ}-6^{\circ}$ ) have been presented by three authors [e.g., Isham et al., 1999; Rietveld et al., 2002; Kosch et al., 2011]. Both Isham et al. [1999] and Kosch et al. [2011] presented data from experiments where the heater employed low duty cycles (to minimize the possible generation of AFAIs) and with the radars operating in scanning modes. Isham et al. [1999] noted that there appeared to be evidence of $O$ - to $Z$-mode conversion occurring in the $F$ region at angles outside the Spitze region, notably between the Spitze angle and magnetic field pointing directions (an angular window of $\sim 6^{\circ}$ width). Kosch et al. [2011] also observed $O$ - to $Z$-mode conversion occurring in the $F$ region, resulting in enhancements in backscatter power at both the topside and bottomside of the $F$ region at 220 and $300 \mathrm{~km}$ altitude.

[10] Rietveld et al. [2002] observed plasma and ion line spectral enhancements in both the $E$ and $F$ region ionosphere using both the EISCAT UHF (931 MHz) and VHF (224 MHz) radars located at Tromsø. They attributed the observed enhancements to both the PGM and PDI. Observations of possible $O$ - to $Z$-mode conversion were observed using the VHF radar, in a vertical pointing direction at heights of between 110 and $120 \mathrm{~km}$ altitude. They speculated that the enhancements could be the result of cavitating turbulence. However, the range resolution of the data $(3.75 \mathrm{~km})$ was not sufficient to make a conclusive deduction.

[11] This paper will present observations of $O$ - to $Z$-mode conversion in a sporadic $E$ layer using the EISCAT Svalbard Radar, the SPEAR ionospheric heater, and the Co-operative UK Twin Auroral Sounding System (CUTLASS) SuperDARN radars.

\section{Instrumentation}

\subsection{SPEAR}

[12] The Space Plasma Exploration by Active Radar (SPEAR) [Wright et al., 2000] facility is a high-power ionospheric heating facility located on the island of Spitzbergen, in the Svalbard archipelago, at a geographic location of $78.15^{\circ} \mathrm{N}\left(75.43^{\circ} \mathrm{N}\right.$ geomagnetic; $\mathrm{L} \sim 15$; magnetic dip angle $\sim 8^{\circ}$ ). It is colocated with both the EISCAT Svalbard radar (ESR) and the Kjell Henriksen Auroral Observatory. The facility consists of $4 \times 6$ array of rhombically broadened crossed-dipole antennas, with a distributed transmitter system consisting of $48 \times 4 \mathrm{~kW}$ transmitters. This configuration results in a frequency-dependent beam width of approximately $14^{\circ} \times 21^{\circ}$ with a gain of $21 \mathrm{~dB}$. The facility has 11 discrete transmission frequencies between $4.45 \mathrm{MHz}$ and $5.82 \mathrm{MHz}$ with a maximum effective radiated power (ERP) of $30 \mathrm{MW}$. During the experiment described in this paper, SPEAR was transmitting in an $O$-mode polarization in a field-aligned pointing direction.

\subsection{EISCAT}

[13] The European Incoherent Scatter (EISCAT) Svalbard Radar (ESR) [Wannberg et al., 1997] is colocated with the 
SPEAR facility. It consists of two radar dishes: a $32 \mathrm{~m}$ fully steerable dish and a $42 \mathrm{~m}$ static dish fixed in a field-aligned position both with a transmitting frequency of $\sim 500 \mathrm{MHz}$ making them sensitive to plasma waves of scale length $\sim 30 \mathrm{~cm}$. The system is able to detect both natural and artificially modified ion-acoustic and Langmuir waves. The resulting ion and plasma line spectra are then analyzed to obtained plasma parameters such as electron density $(\mathrm{Ne})$, electron temperature $(\mathrm{Te})$, ion temperature $(\mathrm{Ti})$ and line of sight ion velocity $(\mathrm{Vi})$.

[14] The data presented in this paper are from both the $32 \mathrm{~m}$ and $42 \mathrm{~m}$ dish, with the $32 \mathrm{~m}$ fixed in a field-aligned position. The pointing direction of the dishes results in observations outside the Spitze angle (ESR magnetic dip angle $\sim 8^{\circ}, \theta_{c} \sim 3^{\circ}-4^{\circ}$ ). Ion line data were collected on both dishes, with plasma line data collected on the $32 \mathrm{~m}$ dish.

[15] The ion line data were obtained on a single channel with a transmitter frequency of $499.85 \mathrm{MHz}$. The heightdiscriminated ion line data were obtained over an altitude range of 43-507 km with a variable resolution of 2.2 $4.5 \mathrm{~km}$. The resolutions are a result of oversampling the $30 \mu$ s baud length of the 30 bit alternating code [Lehtinen and Häggström, 1987] with a factor of 2. The plasma line spectra were also obtained on a single channel from the same pulse with a transmitter frequency of $499.85 \mathrm{MHz}$. The data were collected using a $1.67 \mathrm{MHz}$ wide frequency band offset from the transmitter frequency. The offset frequency was initially set to $\pm 4.0 \mathrm{MHz}$ before changing to $\pm 4.8 \mathrm{MHz}$ for the $(+)$ upshifted and $(-)$ downshifted plasma lines. The resulting height-discriminated plasma line data were taken over an altitude range $41-311 \mathrm{~km}$ with a resolution of $100 \mathrm{~m}$. The temporal resolution of both the ion and plasma line data was $6.0 \mathrm{~s}$.

[16] Unfortunately there are no data available from the EISCAT Svalbard Dynasonde during the experiment. However, dynasonde data from 09:24:00 UT (shortly before the experiment began) are available, which indicated the presence of an $E$ layer with $f_{o} E=4.776 \mathrm{MHz}$.

\subsection{SuperDARN}

[17] The Hankasalmi radar is an HF coherent backscatter radar system located in Finland and forms part of the SuperDARN array. It is ideally situated for making observations of the heated volume over Svalbard [e.g., Robinson et al., 2006]. The radar was operating in the HF band between $9.9 \mathrm{MHz}$ and $9.985 \mathrm{MHz}$ and was employing a dual scan mode: channel A with a 16 beam scan, with each beam separated by $3.24^{\circ}$, resulting in a total azimuthal scan of $52^{\circ}$ while channel B employed a single beam (beam 9 out of the 16 available beams) scan. Beam 9 overlies the SPEAR and ESR location. The beam was gated into 75 range bins of $45 \mathrm{~km}$ in length, with a distance to the first range gate of $180 \mathrm{~km}$, resulting in range gates $40-45$ typically overlying the SPEAR location $\left(78.15^{\circ} \mathrm{N}\right)$, depending on propagation conditions [Yeoman et al., 2008a, and references therein]. The radar was operating in a high temporal mode sounding on a single frequency of $9.9 \mathrm{MHz}$, with a dwell (integration) time of $3 \mathrm{~s}$. Data will be presented from channel B in this paper.

[18] The radars use coherent backscatter to measure convection flows in the ionosphere. Backscatter of the radar radio waves with wave vector $k_{r}$, occurs from ionospheric field-aligned irregularities (FAI) with wave vector $k$, only when the Bragg condition $k= \pm 2 k_{r}$ is satisfied. As mentioned earlier, the SPEAR facility can generate artificial FAIs (AFAIs), where the heater beam couples to upper hybrid waves at the upper hybrid resonance height. These then act as targets for the CUTLASS radars. The detection of AFAIs by HF radar then provides a signature of the TPI occurring.

\section{Observations}

[19] On 5 July 2010, from 10:00 to 13:00 UT, SPEAR was operating at a heater frequency, $f_{h}=4.45 \mathrm{MHz}, O$-mode polarization with a $5 \mathrm{~min}$ on, $5 \mathrm{~min}$ off periodicity. The beam was pointing field aligned $\left(184.5^{\circ} \mathrm{az} ., 81.6^{\circ} \mathrm{el}\right.$.) with an ERP $\sim 16 \mathrm{MW}$. The beam width is $14^{\circ}$ by $21^{\circ}$ wide, allowing part of the heater beam to provide interactions at the Spitze angle $\left(\sim 3^{\circ}-4^{\circ}\right.$ at SPEAR). The EISCAT data presented here are taken using the IPY experimental code which uses both the 42 and $32 \mathrm{~m}$ dishes, pointing in a field-aligned direction ( $\sim 4^{\circ}-5^{\circ}$ outside the Spitze angle), allowing simultaneous ion and plasma line data to be taken. The radar was running from 10:27-10:47 UT. Conditions were geomagnetically quiet with a $K p$ index $=1$.

[20] Figure 1a indicates a range-time-intensity plot from beam 9 of the CUTLASS Finland radar over magnetic latitude $70^{\circ} \mathrm{N}-80^{\circ} \mathrm{N}$ (range gates $25-51$ ). The data are color coded according to the intensity of backscatter power in $\mathrm{dB}$. Figure $1 \mathrm{~b}$ indicates the ionospheric electron density $(\mathrm{Ne})$, as measured by both ESR dishes, from 10:28-10:47 UT over an altitude range of 70-200 km, with the corresponding density scale shown to the right of the plot. Figure 1c shows the spectral power of the central ion line spectral peak at specific altitudes as measured by the ESR $42 \mathrm{~m}$ dish (colorcoded according to the box shown at the left-hand side in the plot). SPEAR-on periods (10:30-10:35 and 10:4010:45 UT) are marked at the top of Figure 1 by a red bar.

[21] The naturally occurring sporadic $E$ layer is clearly seen in Figure $1 \mathrm{~b}$ as enhancements in Ne between 95 and $110 \mathrm{~km}$. A patch of backscatter occurring at the SPEAR latitude is also observed by beam 9 of the CUTLASS Finland radar between 10:35 and 10:45 UT as shown in Figure 1a which could be a signature of the same layer. The fact that it is only observed for this $10 \mathrm{~min}$ period could be due to the changing ionospheric conditions which would in turn affect that radar beam propagation path. The CUTLASS data are discussed in more detail in section 4.3 of this paper.

[22] The $E$ layer, as observed by the ESR, persists throughout most of the interval, disappearing slightly between 10:31-10:34 UT. What is also evident in Figure $1 \mathrm{~b}$ are the large enhancements observed in $\mathrm{Ne}$ which coincide with SPEAR-on periods, most prominently from 10:40 10:45 UT. These apparent SPEAR-induced enhancements in $\mathrm{Ne}$ are 'false' and are merely artifacts of the fitting routine applied to the SPEAR enhanced spectra. This is demonstrated in Figures 2 and 1c. Figure 2 shows the normalized average ion line spectra from 10:39:30-10:40:00 UT (SPEAR-off period) and 10:40:00-10:40:30 UT (SPEAR-on period) at $108 \mathrm{~km}$ altitude. The spectrum during the off period (shown red) is typical of that in the $E$ region, consisting of a single central broad peak. There is a clear enhancement which dominates at the frequency of the central peak during the SPEAR-on period (shown in green in Figure 2). Additional ESR measurements of the electron 


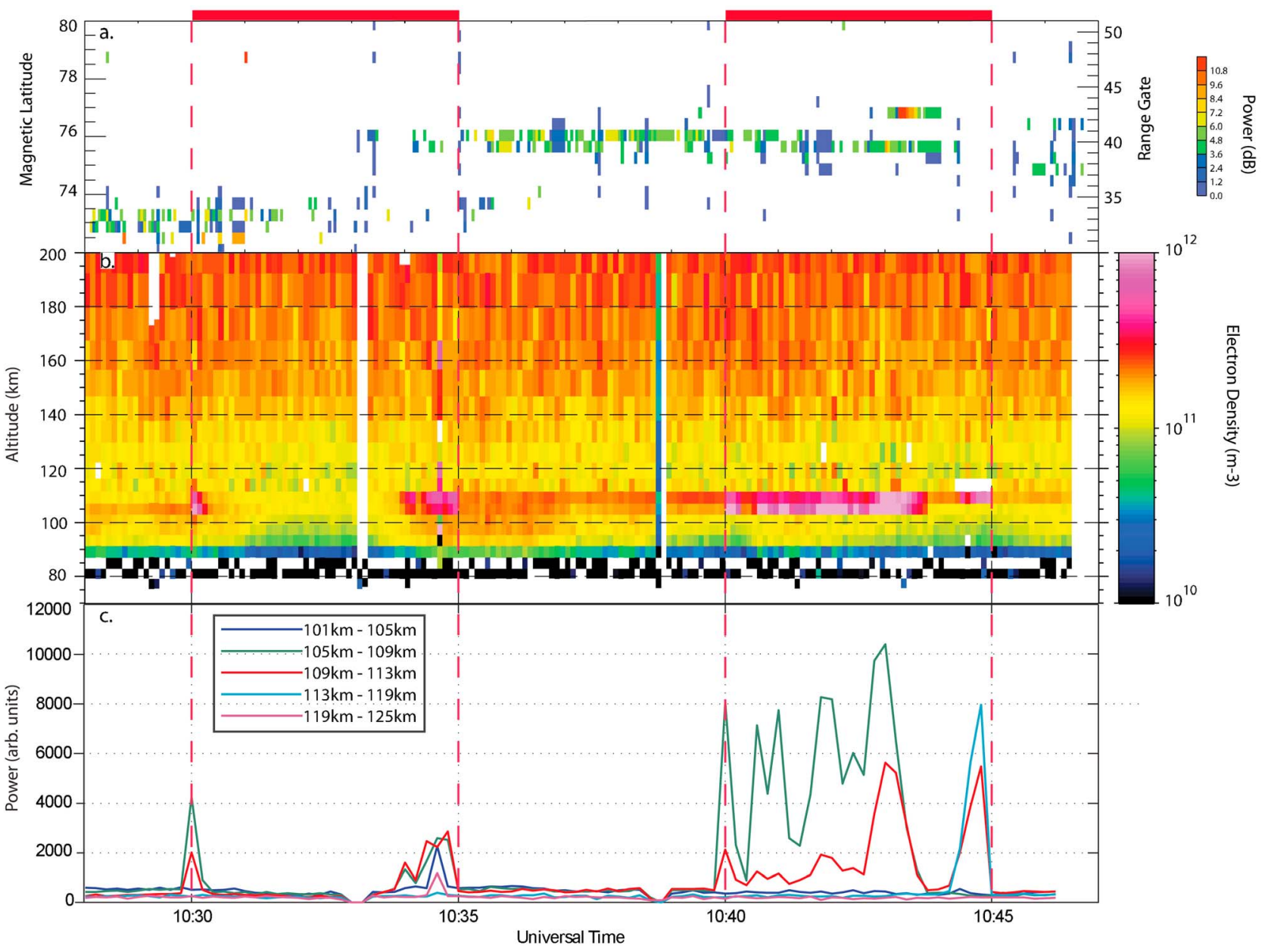

Figure 1. Data from the heating experiment on 5 July 2010, 10:27-10:47 UT, where the SPEAR periods (10:30-10:35 UT and 10:40-10:45 UT) are marked by solid red bars at the top. (a) Range-time-intensity plot of backscatter power from beam 9 of the Co-operative UK Twin Auroral Sounding System (CUTLASS) Finland radar. Both magnetic latitude and range gate are shown on the $y$ axis. The data are color coded according to the scale to the right of the plot. (b) Ionospheric electron density as measured by the EISCAT Svalbard Radar (ESR) $42 \mathrm{~m}$ dish. The data extend from 80 to $200 \mathrm{~km}$ in altitude and are color coded according to the scale to the right of the plot. (c) Amplitude of the ion line spectra central peak as measured by the ESR $42 \mathrm{~m}$ dish as a function of altitude.

temperatures at the same altitude (not shown) indicate apparent temperature decreases, which also indicate the spectra have been artificially modified. The analysis software cannot accurately fit to the modified spectra due to the fact that is either too narrow, or more likely, that the central peak is too large, both of which apply to the SPEAR enhanced spectra. Figure 1c shows the temporal variation of this central ion line peak throughout the experiment. There are clear enhancements in the spectral power of the central ion line, which correspond to the SPEAR-on times of 10:30 10:35UT and 10:40-10:45 UT. The enhancements also dominate at different altitudes, increasing from 104-109 km at the start of the interval to $109-113 \mathrm{~km}$ at $10: 43 \mathrm{UT}$. The altitude of the observations place the enhancements clearly in the collisional $E$ region. These enhancements of the central ion line peak have been interpreted in the past as an indication of the heater beam driving the PGM instability, producing low-frequency ion acoustic waves. In the event described here, the increased collisional damping effects present in the $E$ region means that the shoulder peaks in the ion line spectra (associated with a PDI interaction) and the central ion line peak (associated with the PGM) have merged into a single peak located at a zero frequency offset from the radar transmission frequency. This makes identification of a specific generation mechanism purely based on the ion line data impossible.

[23] As has been seen previously at SPEAR, the ion line enhancements continue throughout the heater on period, which is in contrast to that usually seen at lower latitudes, where the spectral enhancements are often quenched owing to mode conversion of the heater wave into upper hybrid waves after a few seconds, producing the so-called ion line overshoot effect [Robinson, 1989]. These results in themselves are still to be explained fully though one possibility is a combination of the narrow field of view of the ESR beam and increased temporal variability in the high-latitude ionosphere, through such phenomena as polar cap patches. As discussed by Robinson et al. [2006], these factors could 


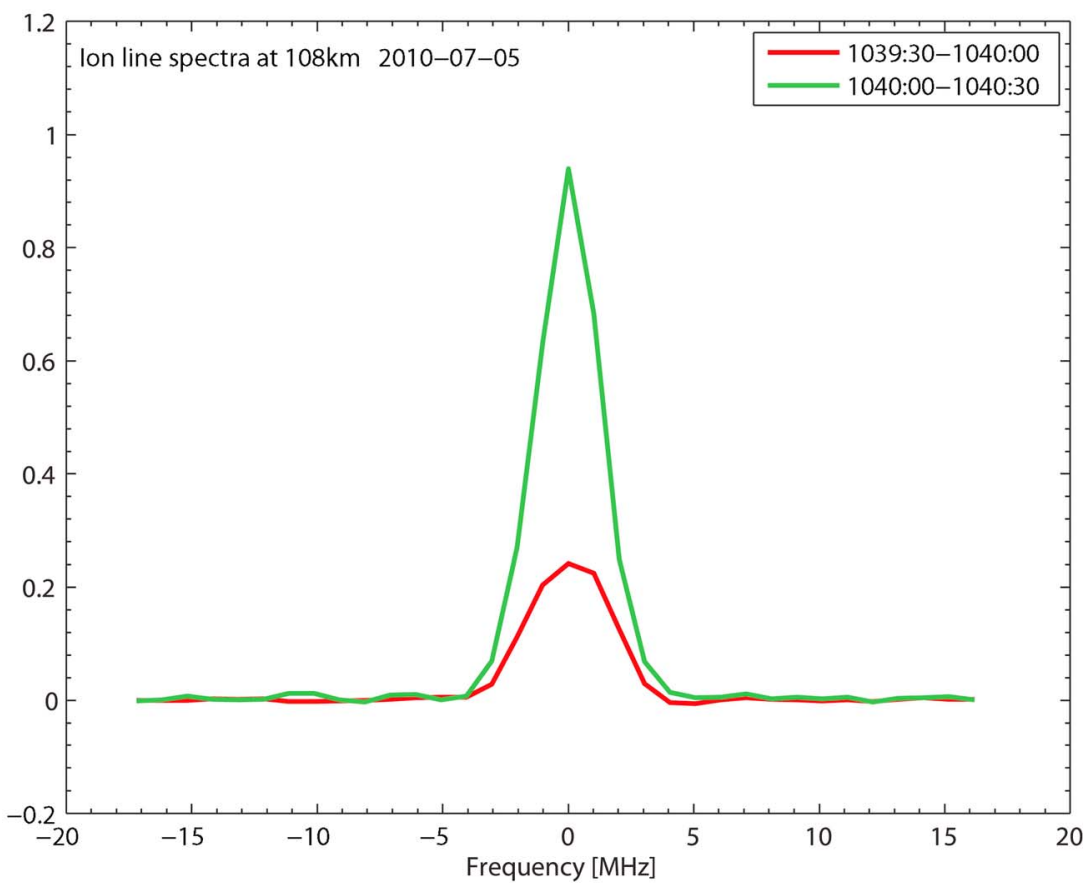

Figure 2. Ion line spectra as measured by the ESR, averaged over a $30 \mathrm{~s}$ period during a SPEAR-off period (10:39:30-10:40:00 UT) and a SPEAR-on period (10:40:00-10:40:30 UT) showing the SPEARinduced spectral enhancements.

introduce a higher variability in the strength of the heater beam within the interaction region. The plasma line spectra will be the focus of this paper, however it is prudent to show the analyzed $\mathrm{Ne}$ data to show the extent of the naturally occurring $E$ region and also that the region remains when SPEAR is switched off.

[24] Plasma line spectra were taken using the ESR $32 \mathrm{~m}$ dish in a field-aligned pointing direction. Figure 3 shows height-integrated plasma line spectral power as a function of frequency and time for the $E$ region (Figures $3 \mathrm{a}$ and $3 \mathrm{~b}$ ) and $F$ region (Figures $3 \mathrm{c}$ and $3 \mathrm{~d}$ ) ionosphere from 10:28 to 10:47 UT. Figures $3 \mathrm{a}$ and $3 \mathrm{c}$ show the upshifted plasma line power, and Figures $3 \mathrm{~b}$ and $3 \mathrm{~d}$ show the downshifted plasma line power. The data have a resolution of $16.6 \mathrm{kHz}$. The $E$ region profile is integrated over an altitude range of $41-$ $181 \mathrm{~km}$, while the $F$ region profile is integrated over an altitude range of $171-311 \mathrm{~km}$. It should be noted that the $E$ region and $F$ region spectral power scales are different, owing to the fact that the power observed in the $E$ region was 2 orders of magnitude higher than that observed in the $F$ region. SPEAR-on periods (10:30-10:35 UT and 10:40 10:45 UT) are marked at the top of Figure 3 by a red bar. What is immediately evident is that the $E$ region plasma line spectra are dominated by enhancements at the SPEAR heater frequency, $f_{h}=4.45 \mathrm{MHz}$, and that no such enhancements are observed in the $F$ region spectra. Additionally, the $E$ region enhancements are only observed during the SPEAR-on periods (10:30-10:35 UT, 10:40-10:45 UT). The results are clear signatures of the heater beam interacting with the ionospheric plasma and generating Langmuir waves in the $E$ region. There is a clear dominance in spectral power in the upshifted plasma line, indicating a preferential enhancement of Langmuir waves propagating toward the radar. There is also a high degree of variability in the spectral power at $4.45 \mathrm{MHz}$ throughout the SPEAR-on periods, as was also seen in the ion line data, particularly from 10:40 10:45 UT. Throughout the period, the SPEAR heater power remained approximately constant at 16 MW (ERP) thus suggesting the variability was due to ionospheric conditions. This variability is also temporally symmetric between the up and downshifted lines, despite the difference in overall power. The data from the $F$ region (Figures $3 \mathrm{c}$ and $3 \mathrm{~d}$ ) indicate the natural plasma frequency $\left(f_{o} F 2\right)$ remains at approximately $4.7 \mathrm{MHz}$ throughout the interval. The magnitude of the spectral power enhancements at $4.7 \mathrm{MHz}$ in the $F$ region do increase during the second SPEAR-on period (10:40-10:45 UT) but there is no temporal correlation to the $E$ region enhancements at $4.45 \mathrm{MHz}$. In addition the $F$ region enhancements at $4.7 \mathrm{MHz}$ continue during the SPEAR-off period (10:45-10:50 UT). The data indicate that there is no evidence of any spectral enhancements corresponding to SPEAR heating effects in the $F$ region plasma line spectra. This is consistent with the fact that the enhancements are observed in the $E$ region spectra, resulting in the absorption of the heater beam at this lower altitude. The $F$ region plasma lines suddenly become stronger at 10:34 UT, which correlated with the onset of the sporadic $E$ region (the large spectral power initially observed at $\sim 10: 34: 00-10: 34: 06$ UT corresponds to a data gap, which is also observed in Figure 1). It is possible that there may be a simultaneous increase of suprathermal electron fluxes which will act to enhance the natural plasma lines in the $F$ region. Again, there is a large variability in the observed $F$ region spectral power, with larger power in the upshifted plasma line data. Previous observations of SPEAR enhanced height integrated plasma line data covering the altitude range 90- 

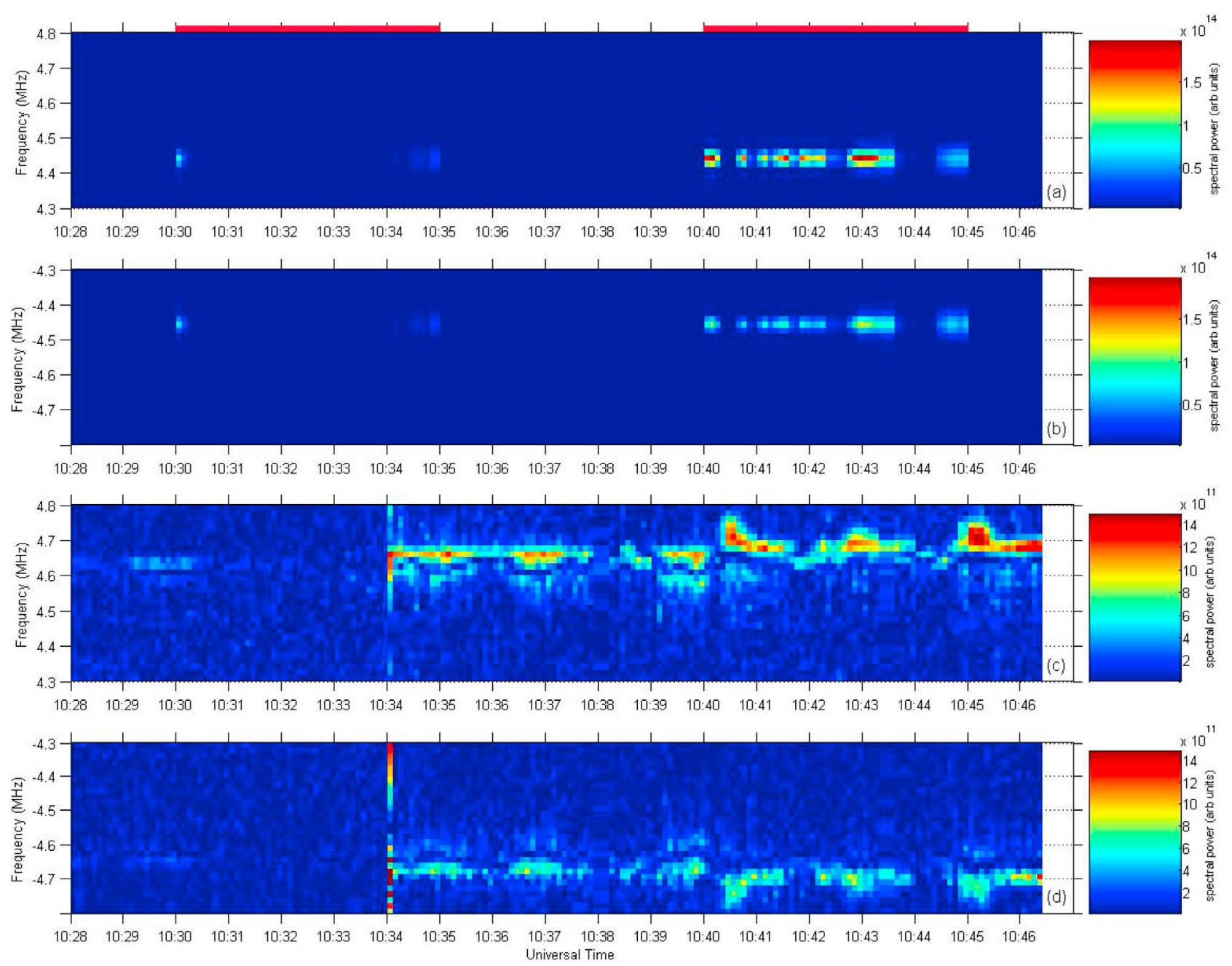

Figure 3. Height-integrated plasma line data at a $6 \mathrm{~s}, 16.6 \mathrm{kHz}$ resolution, as measured by the ESR $32 \mathrm{~m}$ dish. (a, b) Upshifted and downshifted $E$ region data integrated over a height range of 41-181 km. (c, d) Upshifted and downshifted $F$ region data integrated over a height range of $171-311 \mathrm{~km}$. Spectral enhancements are clearly observed in the $E$ region data at the SPEAR frequency, $f_{h}=4.45 \mathrm{MHz}$, during the SPEAR-on periods (10:30-10:35 UT and 10:40-10:45 UT) marked by red bars at the top of the plot.

$315 \mathrm{~km}$ [Dhillon et al., 2007] have also shown large variability in the spectral power during the SPEAR-on periods. The data presented in their paper did not display any significant difference in spectral power magnitude between the upshifted and downshifted plasma lines, as is shown here. Observations made at lower latitudes, using the EISCAT Tromsø facilities in northern Norway, by Rietveld et al. [2002] however, do indicate difference in spectral power magnitude between the upshifted and downshifted plasma lines as measured in the $E$ region between $110-140 \mathrm{~km}$ altitude.

[25] The $E$ region spectral enhancements at the heater frequency, $f_{h}=4.45 \mathrm{MHz}$ were investigated further. The data were height separated to a spatial resolution of $100 \mathrm{~m}$ which represents the highest spatial resolution heater enhanced plasma line data published to date. The results from this are shown for both the upshifted (Figure 4a) and downshifted (Figure 4b) plasma line. The data are plotted from 10:38-10:47 UT to focus on the spectral enhancements during the second SPEAR-on period from 10:40-10:45 UT.
Figures $4 \mathrm{a}$ and $4 \mathrm{~b}$ are on different spectral power scales owing to the fact that upshifted plasma line enhancements are larger than the downshifted enhancements.

[26] The plasma line enhancements are observed to occur initially at the bottomside of the $E$ region at $107.5 \mathrm{~km}$ altitude before the two distinct interaction regions form at 10:43:00 UT which last for $48 \mathrm{~s}$. These regions occur at $107.5 \mathrm{~km}$ and $109 \mathrm{~km}$, each with an approximate spatial extent of $\sim 300 \mathrm{~m}$ and correspond to the bottomside and topside of the sporadic $E$ layer. This is suggestive of a conversion of the $O$-mode heater wave into a $Z$-mode wave at the bottom of the $E$ region. The enhancements observed at the bottomside of the layer at $107.5 \mathrm{~km}$ are typical signatures of $O$-mode-induced Langmuir turbulence. At 10:43:00 UT the conditions outlined in equation (2) are satisfied, resulting in the propagation of the $Z$-mode wave to the topside of the $E$ region where it undergoes mode conversion into Langmuir waves.

[27] As mentioned earlier, there were no dynasonde data available during this period. However, at 09:24 UT data 

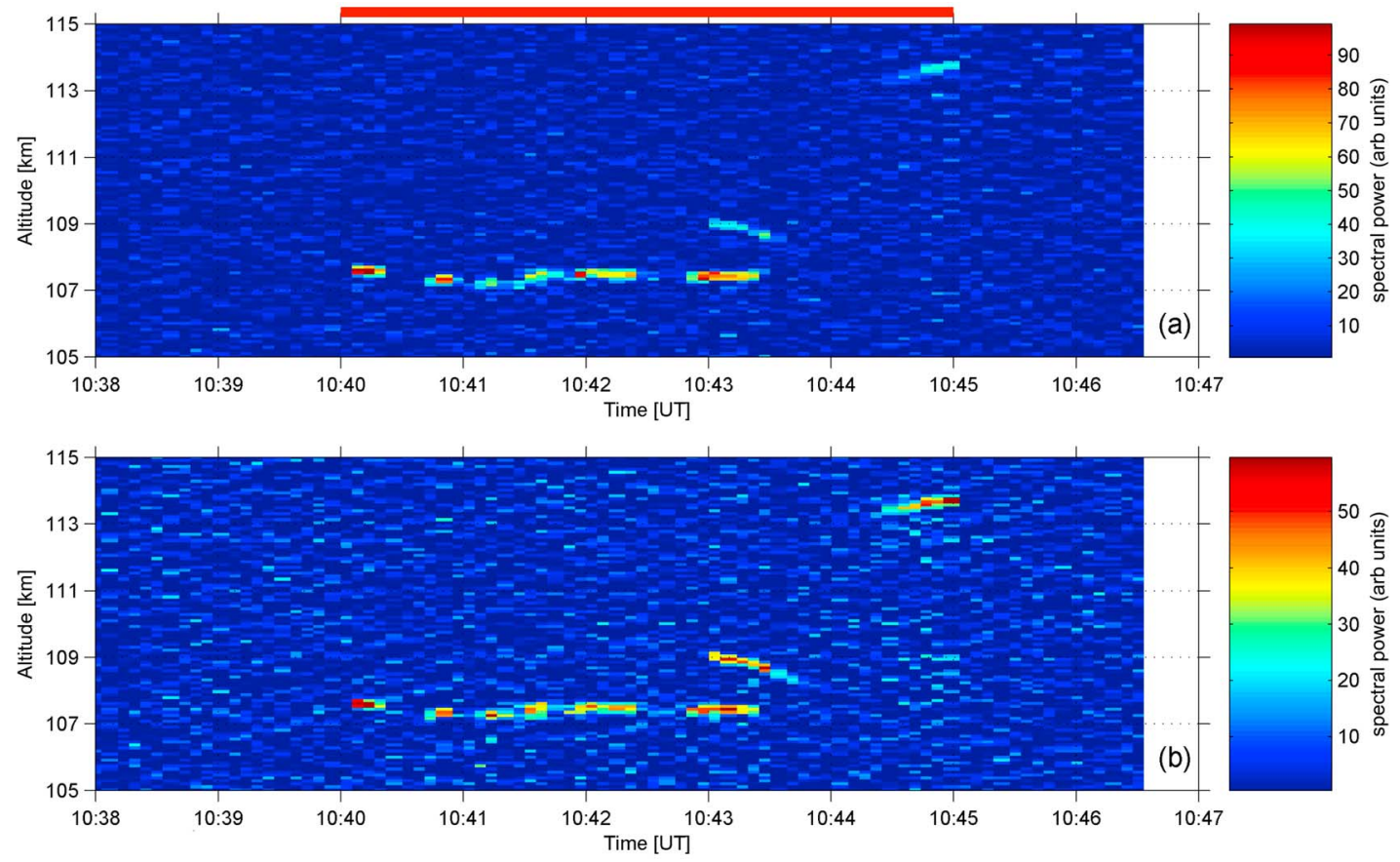

Figure 4. Altitude-separated 4.45 MHz plasma line data at a $6 \mathrm{~s}$ and $100 \mathrm{~m}$ resolution for the (a) upshifted spectral components and (b) downshifted spectral components from 10:38-10:47 UT. The altitude range covers the bottomside and topside of the sporadic $E$ layer, from 105 to $115 \mathrm{~km}$. The SPEAR-induced enhancements can clearly be seen, initially at $107.5 \mathrm{~km}$, with a second region appearing at 10:43:00 UT at $\sim 109 \mathrm{~km}$. The enhancements disappear from 10:43:48 to 10:44:24 UT before reappearing in a single layer at $113 \mathrm{~km}$.

from the EISCAT dynasonde, which is colocated with SPEAR, were available. They indicated the presence of an $E$ layer with $f_{o} E=4.776 \mathrm{MHz}$. Incorporating this, into equation (2), along with the parameters defined earlier in the paper for the SPEAR $\left(f_{e} \sim 1.4 \mathrm{MHz}, f_{h}=4.45 \mathrm{MHz}\right)$ indicate that the condition for $Z$-mode propagation was satisfied, $(4.45 \mathrm{MHz}<4.776 \mathrm{MHz}<5.183 \mathrm{MHz})$.

[28] Between 10:43:48 UT and 10:44:24 UT no plasma or ion line spectral enhancements are observed in the $E$ region. At 10:44:24 UT the plasma enhancements reappear at a higher altitude of $113.5 \mathrm{~km}$, as shown in Figure 4. The corresponding enhancements in the central ion line also reappear, as is seen in Figure 1c. There is a large degree of variability in the spectral power of both the plasma line components even at this high spatial resolution with the spectral power doubling between adjacent range gates on several occasions. Additionally the bottomside interaction region varies in altitude by between 200 and 300 m over 1 to 2 data dumps $(6-12 \mathrm{~s})$.

[29] Although the initial topside enhancements are observed at $109.2 \mathrm{~km}$, they descend to $108.3 \mathrm{~km}$ over the $48 \mathrm{~s}$ period at a rate of $18.75 \mathrm{~m} \mathrm{~s}^{-1}$. This descent in the interaction region would indicate a lowering of the $Z$-mode reflection height, or a decrease in the plasma density at those heights. Since the heater frequency and electron gyrofrequency do not change throughout this period (at least not significantly enough over this time period or altitude range) then this would suggest a decrease in the plasma density is the most likely cause. There is a small decrease also in the bottomside enhancements during this time which, when coupled with the fact that the enhancements disappear completely from 10:43:48$10: 44: 24$ UT, would also suggest that there is a general decrease in the plasma density across the region. Both of these observations would be consistent with a thinning of the $E$ region over this time period. What is interesting is that the $Z$-mode-wave-induced topside enhancements, most notably in the downshifted plasma line, appear to have a delay of approximately $12 \mathrm{~s}$ from the $O$-mode-induced enhancements observed at the bottomside. This could be due to the previously discussed ionospheric variability introducing different onset and stop times at the topside and bottomside of the $E$ region. It is possible that a decrease of $f_{o} E$ with time would result in the required conditions, as outlined in equation (2), being met at 10:43:00 UT but at 10:43:40 UT, $f_{o} E<4.45 \mathrm{MHz}$. This would then explain the $12 \mathrm{~s}$ delay between the onset times observed between the two regions. It is uncertain however, how the topside enhancements can continue after the bottomside enhancements have ceased, from 10:43:36-10:43:48 UT. An introduced propagation delay of the heater beam between the two regions can be ruled out given the fact that they are only separated by $800 \mathrm{~m}$. Although the $Z$-mode wave is quasi-electrostatic, this would still only introduce a maximum delay (assuming electrostatic propagation, with $\mathrm{Te}=360 \mathrm{~K}$ ) of $\sim 10 \mathrm{~ms}$. Similar propagation delays of several $\mathrm{ms}$ have also been observed in previous observations of $Z$-mode waves [James, 1991].

[30] The enhancements in the downshifted plasma line are of similar magnitude at both the topside and bottomside of the $E$ region, whereas in the upshifted plasma line, the 
enhancements are smaller at the topside of the $E$ region. This is in contrast to the observations made by Rietveld et al. [2002] where they observed stronger topside enhancements. It should be noted that those topside and bottomside enhancements were identified to be separated by $15 \mathrm{~km}$ in altitude, unlike those presented here which had a separation of only 700-1600 m. They were unable to draw firm conclusions as to the nature of the variability; however, they did speculate that it was related to disturbances caused by auroral activity. The results presented in this paper occurred at 10:00-11:00 UT (12:00-14:00 LT) which means that any auroral activity cannot be optically identified. During this period, $K p=1$ and an examination of ground magnetometer data from several stations from the IMAGE magnetometer chain, located on and around Svalbard, (NYA, LYR, HOR, $\mathrm{HOP}$ and $\mathrm{BJN}$ ) indicated no large local magnetic field variability. This also suggests that there was no significant auroral activity during this time.

[31] At 10:44:24 UT, when the enhancements reappear at $113.5 \mathrm{~km}$ the magnitude of the downshifted plasma line enhancements are dominant, in comparison to all previous intervals.

[32] This change in the interaction altitude is also evident in the ion line data shown in Figure 1b, with the interaction region increasing in altitude to $113 \mathrm{~km}$ toward the end of the interval. The ion line data however have a much lower range resolution $(\sim 4 \mathrm{~km})$ so although it can indicate an increase of a few $\mathrm{km}$ in the altitude interaction, as occurs at 10:44:24 UT, the two distinct interaction regions in the $E$ region observed from 10:43:00-10:43:48 UT in the plasma line data cannot be distinguished.

[33] These results represent not only the highest spatial resolution plasma line observations obtained during a heating experiment, but also the first evidence of $O$ - to $Z$-mode conversion using the SPEAR facility.

\section{Discussion}

[34] Two aspects of the data presented in section 3 require further discussion and explanation: (1) the generation mechanism for the observed enhancements and (2) the fact that the topside enhancements were observed at an angle outside the Spitze angle. In addition, the CUTLASS Finland radar data will be discussed in more detail.

\subsection{Possible Generation Mechanisms}

[35] Several theories exist as to the exact nature of observed ion and plasma line enhancements in the $E$ region. Observations of SPEAR-induced ion and plasma line enhancements in both $E$ and sporadic $E$ have been observed previously by Dhillon et al. [2009]. In their paper they attribute the former to interactions via both the PDI and PGM. In the case of the sporadic $E$ layer, their results proved inconclusive as to an exact generation mechanism. Although plasma line data were presented, only the integrated data were available, which were averaged over a height range of 90-315 km.

[36] Eliasson [2008] presented a numerical two-scale simulation in $F$ region plasma which showed that $Z$-mode waves which propagate to the topside of the layer would then form Langmuir cavitons which would in turn account for the enhanced plasma line observations. However, since the simulation was carried out for $F$ region plasma the scale lengths used in the model were far larger than those for a sporadic $E$ layer.

[37] Rietveld et al. [2002] also showed results of heating of sporadic $E$ region. They also saw significant enhancements from both the PDI and PGM. Their results suggest that HF pump induced Langmuir turbulence is occurring in the $E$ region in a similar manner to that in the $F$ region. However, they estimated the scale height of the $E$ region during the experiment to be between $5 \mathrm{~km}$ and $10 \mathrm{~km}$. It is known that the large electron density gradients present in sporadic $E$ layer result in greatly reduced scale heights. It was shown by Djuth [1984] that the scale height may be $\sim 0.2-1 \mathrm{~km}$ or less. Under these conditions the thresholds for the generation of both the PGM and PDI become too large, making it difficult for them to be viable options for the enhancements observed in this paper.

[38] A theory was presented by Djuth and Gonzales [1988] whereby mode conversion along vertical density gradients in the sporadic $E$ layer at the interaction height would result in the formation of cavitons (localized density depletions filled with Langmuir oscillations) which could be responsible for the observed enhancements.

[39] The data presented here suggest that caviton related Langmuir turbulence could play a significant role in explaining the enhanced ion and plasma line observations. If this is the case then the plasma line data indicate two distinct interaction regions at the topside and bottomside of the sporadic $E$ layer where such structures exist.

[40] Estimates can be made of the electric field thresholds for both the PGM and PDI and compared to that of the SPEAR pump electric field. Assuming no absorption or swelling, an ERP of $16 \mathrm{MW}$ results in an electric field strength of $0.29 \mathrm{~V} \mathrm{~m}^{-1}$ (using equation (2.1) from Robinson [1989]) at an altitude of $108 \mathrm{~km}$. Calculations using equations (6) and (14) from Stubbe and Kopka [1980], with Te = $\mathrm{Ti}=360 \mathrm{~K}, \mathrm{Ne}=1 \times 10^{11} \mathrm{~m}^{-3}$ and a collision frequency of $1 \times 10^{4} \mathrm{~s}^{-1}$, gives a threshold electric field of $0.45 \mathrm{~V} \mathrm{~m}^{-1}$ for the PDI and a value of only $10 \%$ higher for the PGM. The higher collision frequency in the $E$ region makes this threshold value higher than that observed in the $F$ region. However, this calculation ignores the effect of the sharp density gradient, which decreases the resonance region and increases the threshold of the PGM. Alternatively, using a scale height of $1 \mathrm{~km}$ and equation (1) from Muldrew [1978], the threshold value for the PGM becomes $0.6 \mathrm{~V} \mathrm{~m}^{-1}$. Additionally, the calculated value for the SPEAR electric field strength does not take into account swelling of the pump wave near the reflection height which will serve to increase the electric field such that it may well exceed the threshold for the PGM. The calculations also do not take into account such factors as $D$ region absorption. The spectral resolution of the plasma line data $(16.6 \mathrm{kHz})$ also means that an exact generation mechanism cannot be discerned. If the induced enhancements were a result of cascade turbulence (such as the PDI) distinct cascade lines would be observed in the plasma line spectra, offset by the ion-acoustic frequency, from the enhancements at the SPEAR frequency of $4.45 \mathrm{MHz}$. The collisional nature of the plasma also means that specific instability processes which would be identified by enhancements of either the central peak or shoulder peaks of the 


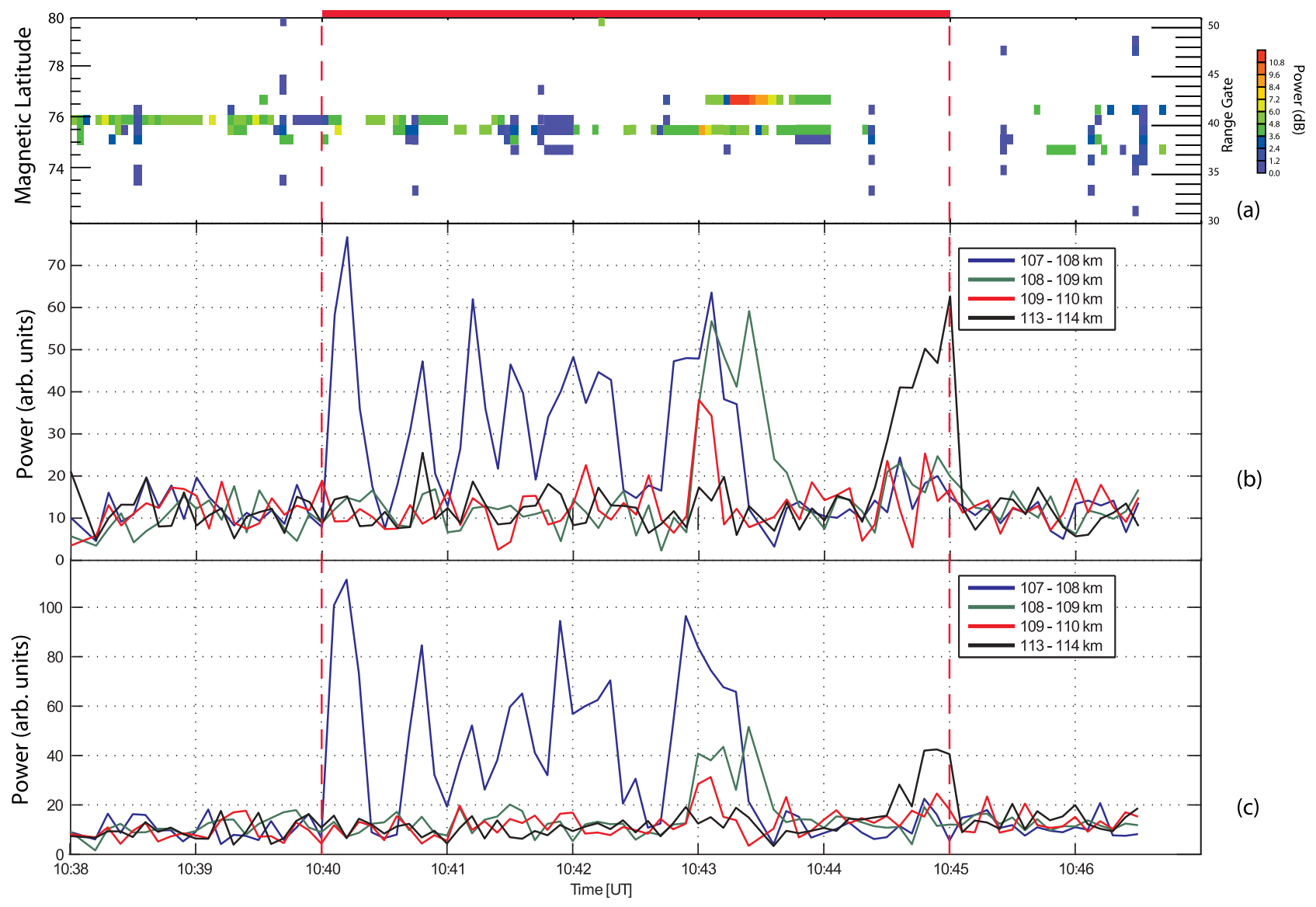

Figure 5. (a) Range-time-intensity plot of backscatter power from beam 9 of the CUTLASS Finland radar. The data are color coded according to the scale to the right of the plot. (b, c) Downshifted and upshifted plasma line intensity for three altitude ranges $(107-108 \mathrm{~km}, 108-109 \mathrm{~km}$, and $113-114 \mathrm{~km})$ as measured by the EISCAT Svalbard radar. The additional backscatter patch observed by the Finland radar (seen at range gate 43 from 10:43:03 to 10:44:03 UT) coincides with a decrease in the magnitude of the $E$ region plasma enhancements. The 12 and $6 \mathrm{~s}$ time differences between the decreases in plasma line power between the bottomside $(107-108 \mathrm{~km})$ and the topside $(108-109 \mathrm{~km})$ enhancements can be seen in the downshifted and upshifted plasma line data, respectively.

spectrum cannot be distinguished. As such it is difficult draw a conclusion regarding the generation mechanism.

\subsection{Angular Extent of the Observations}

[41] Two of the three previous studies examining possible $O$ - to $Z$-mode conversions have focused on the $F$ region only [Isham et al., 1999; Kosch et al., 2011]. Both studies used the EISCAT Tromsø heater in a low duty cycle and employed scanning radar modes with the UHF radar. In both these cases it was pointed out that the results could not be explained fully by current theories. In the case of the observations of Isham et al. [1999], the large angular width of the observations of the $Z$-mode enhancements $\left(6^{\circ}\right.$, between field aligned and the Spitze angle) was difficult to reconcile with the predicted angular width of $<1^{\circ}$ as suggested by Mjølhus [1990]. It was shown, however, by Mishin et al. [2001] that the presence of small scale FAI could account for this increased angular range over which the $Z$-mode enhanced backscatter was observed. However, the power profile data presented by Isham et al. [1999] indicated that such irregularities were not present. Kosch et al. [2011] used a ray tracing model in conjunction with data from the UHF Tromsø radar and colocated dynasonde to indicate observations of $O$ - to $Z$-mode conversion occurring over a $2^{\circ}-3^{\circ}$ angular width. The experiment specifically used the heater in a low duty cycle (average ERP $<3.5 \mathrm{MW}$ ) to reduce the possibility of AFAI generation which could, in turn, cause a widening of the angular extension of the enhancements.

[42] In the case presented in this paper, both the heater beam and the ESR were static in a field-aligned pointing direction, which is approximately $4^{\circ}$ outside the Spitze angle. The exact angular width of the observed $Z$-mode interaction region thus cannot be discerned. Figure 1a indicates the presence of FAIs at the SPEAR latitude $\left(75.43^{\circ} \mathrm{N}\right.$ geomagnetic) during the experiment. It is postulated that the data support the theory of Mishin et al. [2001], whereby the presence of FAIs (as observed by the CUTLASS Finland radar) caused a widening of the angular extent of the observed topside $Z$-mode enhancements to a location outside the Spitze angle. This is also consistent with the results of Isham et al. [1999], who presented strong topside $F$ region 

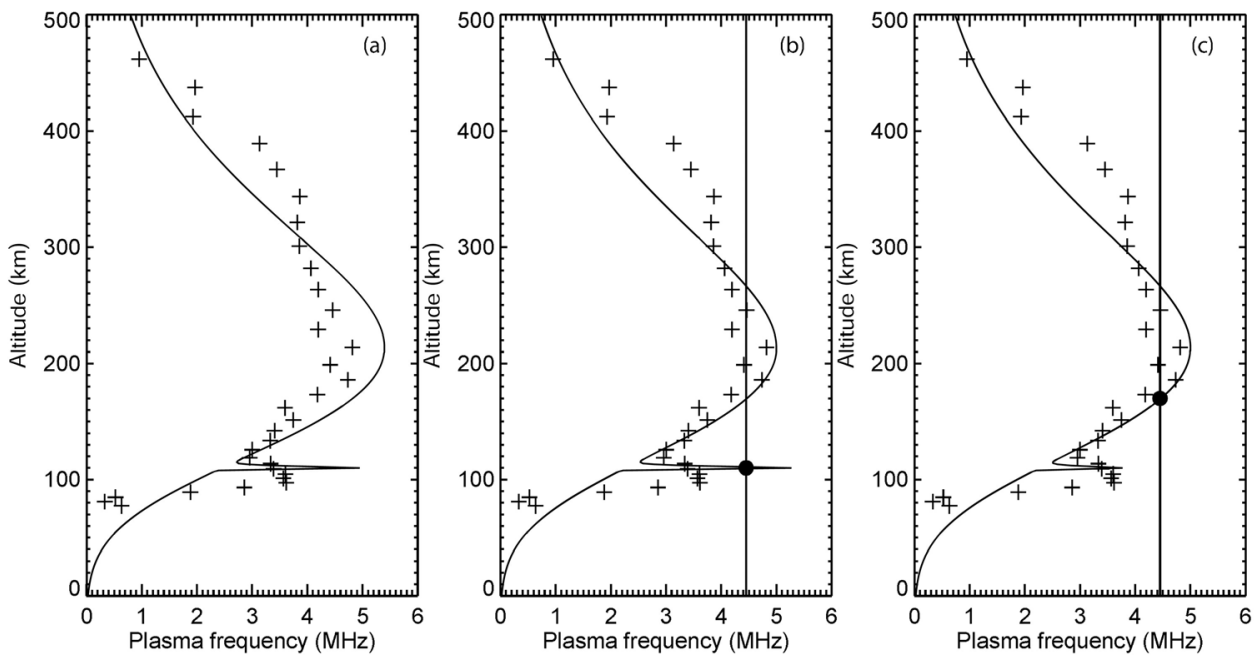

Figure 6. Double-layer Chapman models of the varying ionospheric conditions prevalent during the course of the experiment. (a) Modeled ionospheric profile using additional data from the Tromsø and Svalbard dynasondes and constrained by CUTLASS Finland radar data. This profile was used in a ray tracing algorithm to ascertain the propagation paths for the CUTLASS Finland radar data, the results of which are shown in Figure 7. (b) Ionospheric conditions at Svalbard from 10:40:00 to 10:43:48 UT. (c) Ionospheric conditions at Svalbard from 10:43:48 to 10:44:24 UT. The model was constrained by power profile data from the ESR (indicated by the data points). The heater frequency, $4.45 \mathrm{MHz}$, is marked by a vertical line in Figures $6 \mathrm{~b}$ and $6 \mathrm{c}$, and the resulting interaction height is marked by a black circle.

enhancements between the Spitze angle and a geomagneticfield-aligned position.

[43] Figure 5 indicates a range-time-intensity plot from the CUTLASS Finland radar (Figure 5a) and the upshifted (Figure $5 \mathrm{~b}$ ) and the downshifted (Figure 5c) plasma line ESR data, over the time period 10:38-10:47 UT. The temporal resolution of the CUTLASS and ESR data is 3 and $6 \mathrm{~s}$, respectively. The plasma line spectral power has been averaged over $1 \mathrm{~km}$ bins centered around the interaction regions at the topside $(108-109 \mathrm{~km})$ and bottomside $(107-$ $108 \mathrm{~km}$ ) of the $E$ region and at the altitude where they enhancements reappear at 10:44:24 UT (113-114 km). While the peak spectral power is observed in the upshifted plasma line data there is a significant difference in the relative power between the topside and bottomside enhancements between the upshifted and downshifted plasma line data. In the upshifted plasma line data, the bottomside enhancements are more than double the spectral power of those seen at the topside. However, in the downshifted plasma line data, the enhancements are of similar magnitude. This suggests a greater magnitude of Langmuir waves propagating toward the radar (upshifted plasma line) at the bottomside ionosphere than at the topside. As discussed previously, from 10:43:48-10:44:24 UT, no plasma line enhancements are observed at the SPEAR heater frequency in the ESR data. This is interpreted as a thinning of the $E$ layer with the resulting decrease in plasma density meaning that heater-induced $O$-mode interactions are no longer possible, owing to the heater frequency being fixed at $4.45 \mathrm{MHz}$. As a result, spectral enhancements due to both $O$ - and $Z$-mode interactions are quashed. This can be seen in Figures $5 \mathrm{~b}$ and $5 \mathrm{c}$ as the plasma line enhancements disappear first in the lower altitude range $(107-108 \mathrm{~km})$ and then at the higher altitude range (108-109 km).

\subsection{Artificial Field-Aligned Irregularity Generation}

[44] As seen in Figure 5a from 10:43:03 to 10:44:03 UT an additional patch of backscatter appears in the CUTLASS Finland radar which is mapped to $\sim 1^{\circ}$ latitude north (corresponding to range gate 43) from the patch of naturally occurring FAIs discussed previously. It is postulated that this additional patch is the result of $O$-mode conversion to upper hybrid waves at the upper hybrid height in the $F$ region, resulting in the generation of AFAIs. The decrease in electron density of the sporadic $E$ layer during this time allowed the heater beam to propagate to a higher altitude where the plasma density was sufficiently high to allow the generation of AFAIs. Figures $5 \mathrm{~b}$ and $5 \mathrm{c}$ indicate that the plasma line enhancements observed at the bottomside of the $E$ region began to decrease in magnitude at 10:43:00 UT and 10:43:06 UT, which coincides with the appearance of the additional patch of backscatter. The backscatter power of the patch extends up to $11 \mathrm{~dB}$. The higher magnitude of the backscatter power is consistent with previous observations of such structures [Yeoman et al., 2006]. The SPEAR duty cycle and ERP $(\sim 16 \mathrm{MW})$ is sufficient to generate AFAIs. Such structures have been generated by SPEAR previously in both the $F$ region and upper $E$ /lower $F$ region [e.g., Dhillon et al., 2007] and also at a considerably lower ERP than used in the experiment presented in this paper $(\sim 1 \mathrm{MW}$ [Wright et al., 2009]). Previous observations of SPEARinduced AFAIs have shown the structures can span several range gates resulting in a total spatial extent of $\sim 150 \mathrm{~km}$ [Yeoman et al., 2008b].

[45] To investigate the ionospheric conditions in more detail model double Chapman layer ionospheric profiles were constructed. Figure 6 indicates three profiles, representing the varying prevalent ionospheric conditions which 
Table 1. Parameters Used in the Model

\begin{tabular}{ccccccc}
\hline Figure & Peak Height $1(\mathrm{~km})$ & Scale Height $1(\mathrm{~km})$ & Peak Frequency $2(\mathrm{MHz})$ & Peak Height $2(\mathrm{~km})$ & Scale Height $2(\mathrm{~km})$ & Peak Frequency $2(\mathrm{MHz})$ \\
\hline $6 \mathrm{a}$ & 214 & 100 & 5.4 & 110 & 1 & 2.5 \\
6b & 214 & 100 & 5.0 & 110 & 1 & 3.0 \\
$6 \mathrm{c}$ & 214 & 100 & 5.0 & 100 & 1 & 1.5 \\
\hline
\end{tabular}

occurred during the course of the experiment. Figure $6 \mathrm{a}$ indicates a modeled ionospheric profile derived using power profile data from the ESR (indicated by the data points on the plots), in addition to data from both the EISCAT Svalbard and Tromsø dynasondes. The ionospheric peaks in both the $F$ and $E$ regions are shown at $214 \mathrm{~km}$ and $110 \mathrm{~km}$ altitude. Scale heights of $100 \mathrm{~km}$ and $1 \mathrm{~km}$ were used for the $F$ and $E$ regions, respectively. The additional parameters used in the model for each profile are shown in Table 1. The model was further constrained to match the near-range ground scatter returns observed by the CUTLASS Finland radar at ranges $180-800 \mathrm{~km}$ (not shown), which were characteristic of radar propagation under strong $E$ region critical frequency conditions.

[46] The modeled ionospheric profile shown in Figure 6a allowed a ray tracing of the CUTLASS Finland radar beam (beam 9) at the transmission frequency $(9.9 \mathrm{MHz})$ used in the experiment under realistic ionospheric conditions. Figure 7 shows the beams paths for elevation angles from $5^{\circ}$ to $35^{\circ}$ separated by $0.25^{\circ}$. The approximate location of SPEAR is shown by a green line at a ground range of $\sim 1900 \mathrm{~km}$. It demonstrates that most rays either reflect from the $E$ region to the ground at ranges of less than $800 \mathrm{~km}$, or penetrate the ionosphere. However, some rays may propagate the $\sim 1900 \mathrm{~km}$ to SPEAR latitudes in the $E$ and lower $F$ region. The small number of rays which may achieve this propagation path is also consistent with the data (shown in Figure 5a) which indicates very few patches of backscatter existing at ranges beyond the ground scatter limit at $800 \mathrm{~km}$. Both these facts provide confidence in the model used. The very long range half-hop propagation paths which extend to SPEAR latitudes would be able to achieve the required backscatter conditions at both $E$ and lower $F$ region altitudes above SPEAR. The ray tracing also indicates that the elevation angles for both $E$ and $F$ region scatter from such far range gates are very similar, making it difficult to conclude with certainty that the observed backscatter (both the natural FAIs and the AFAIs) are from the $E$ or $F$ region ionosphere above Svalbard. The fact that the AFAIs appear at higher range gates, however, could be explained by considering the beam path needed to achieve orthogonality to the $B$ field in the lower $F$ rather than the $E$ region. As mentioned earlier the SPEAR facility has routinely generated AFAIs which have an extent of up to four standard size $(45 \mathrm{~km})$ range gates. Such features $(F$ region scatter occurring at higher range gates to approximately colocated $E$ region scatter) have been previously observed in SuperDARN backscatter plots using the HAARP heating facility (B. Bristow, private communication, 2011). Figures $6 \mathrm{~b}$ and $6 \mathrm{c}$ show two suggested ionospheric profiles which would represent the ionospheric conditions that occurred during the SPEAR-on period from 10:40-10:45 UT. Here, the profiles are fitted to the ESR data. In both Figures $6 \mathrm{~b}$ and $6 \mathrm{c}$, the SPEAR frequency, $f_{h}$, is shown as a vertical line at $4.45 \mathrm{MHz}$. The resulting interaction altitude is indicated by the black circle. Figure $6 \mathrm{~b}$ shows the profile from 10:40:00-10:43:48 UT. During this time the sporadic $E$ layer was present such that $f_{o} E>f_{h}$ resulting in the ion and plasma line spectral enhancements observed by the ESR. Figure 6c shows the profile from 10:43:4810:44:24 UT when the reduction in plasma density in the sporadic $E$ layer resulted in $f_{o} E<f_{h}$. During this time the heater beam could propagate to the $F$ region without undergoing absorption and mode conversion in the $E$ region. This resulted in the generation of AFAIs as observed by the SuperDARN Finland radar. At 10:44:24 the plasma line enhancements return, indicating a reappearance of the sporadic $E$ region at a lower altitude. The heater beam is thus once again absorbed in this region, resulting in the plasma

Ray paths for CUTLASS Finland $9.90 \mathrm{MHz}$

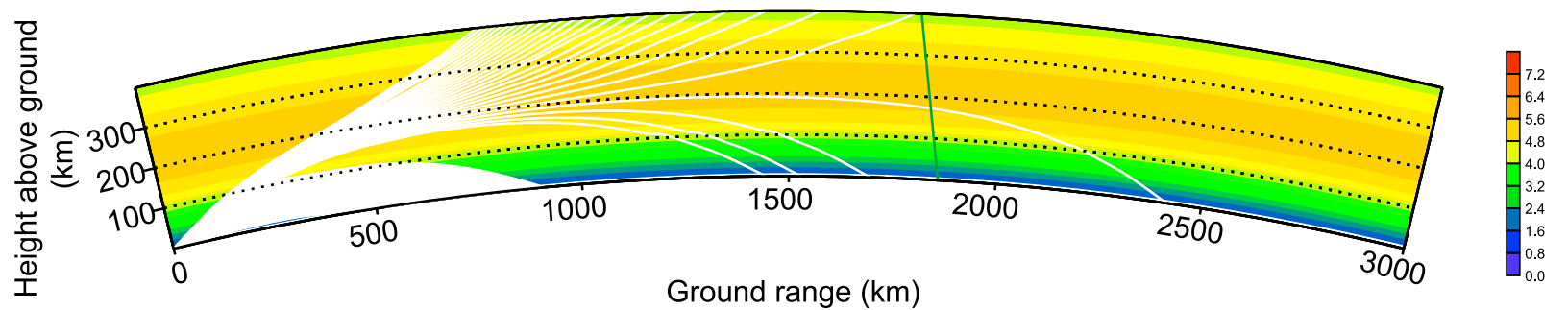

Figure 7. Ray tracing of the CUTLASS Finland radar beams at the transmission frequency used in the experiment $(9.9 \mathrm{MHz})$. The beam paths are shown for elevation angles from $5^{\circ}$ to $35^{\circ}$ separated by $0.25^{\circ}$. The approximate location of SPEAR is shown by a vertical green line at a ground range of $\sim 1900 \mathrm{~km}$. Power profile data from the ESR in addition to data from both the Svalbard and Tromsø dynasondes were both input into the model to obtain realistic propagation conditions (the modeled ionospheric profiles of which are shown and described in Figure 6). 
line enhanced ESR observations and a quenching of the generation of the AFAIs in the $F$ region, as can be seen in Figure 5.

\section{Conclusions}

[47] This paper presented the first results of $O$ - to $Z$-mode conversion of a high-power heater beam occurring in a naturally occurring sporadic $E$ layer in the high-latitude ionosphere $\left(78.15^{\circ} \mathrm{N}\right)$. The SPEAR facility was employing a $5 \mathrm{~min}$ on/ 5 min off CW mode at a frequency of $4.45 \mathrm{MHz}$, in a fieldaligned pointing direction with an ERP $\sim 16 \mathrm{MW}$. Enhancements in the plasma and ion line spectra, as measured by the colocated ESR, were observed. The high-resolution plasma line data $(100 \mathrm{~m})$ indicated two separate enhancement regions, corresponding to the topside and bottomside of the sporadic $E$ layer. The critical frequency in the $E$ region in relation to the heater frequency allowed mode conversion of the $O$-mode heater wave into a $Z$-mode wave to occur at the bottomside of the $E$ layer. The resulting $Z$-mode wave propagated through the $E$ region resulting in a second interaction region forming simultaneously at the topside of the layer. Each interaction region extended $\sim 300-600 \mathrm{~m}$ in altitude, with distinct structure observed down to $100 \mathrm{~m}$ resolution. It is postulated that owing to the small-scale heights present in the sporadic $E$ region, the enhancements are representative of caviton-induced Langmuir turbulence. However, the coarse spectral resolution of the plasma line data, in addition to the single peaked ion line spectra, makes this impossible to confirm absolutely, as frequency enhancements attributed to the different interaction mechanisms cannot be directly discerned. The decrease in electron density of the sporadic $E$ layer, allowed the heater beam to penetrate through the layer and propagate to a higher altitude where it then generated upper hybrid waves resulting in the formation of AFAIs. The signatures of these were observed as coherent backscatter targets using the CUTLASS Finland HF radar. The reappearance of the sporadic $E$ region then resulted in the heater beam again being absorbed at this lower altitude. Plasma and ion line spectral enhancements are then again observed in the ESR data, this time at a slightly higher altitude of $113.5 \mathrm{~km}$.

[48] The $Z$-mode enhanced spectra are observed to occur outside the Spitze angle. It is thus postulated that the presence of FAIs, which are observed by the CUTLASS Finland radar, could account for this.

[49] A ray tracing model was presented for the CUTLASS Finland radar which showed that, under the ionospheric conditions present at the time propagation paths from the radar could observe backscatter in both the $E$ and $F$ region above SPEAR adding confidence in the proposed interpretation of the data.

[50] Acknowledgments. L.J.B. and the SPEAR heating facility are funded by the Norwegian Research Council, grant 191628. The EISCAT scientific association is funded and operated by the research organizations of Norway, Sweden, Finland, Japan, China, the United Kingdom, and Germany. The operations of the CUTLASS radars are funded by the Radio and Space Plasma Physics Group, University of Leicester, UK, and the Finnish Meteorological Institute. We would also like to thank the staff at the EISCAT Svalbard Radar for technical support during the experiment.

[51] Robert Lysak thanks the reviewers for their assistance in evaluating this paper.

\section{References}

Baddeley, L. J., T. K. Yeoman, D. M. Wright, J. A. Davies, K. J. Trattner, and J. L. Roeder (2002), Morning sector drift-bounce resonance driven ULF waves observed in artificially induced HF radar backscatter, Ann. Geophys., 20, 1487-1498, doi:10.5194/angeo-20-1487-2002.

Budden, K. G. (1980), The theory of radio windows in the ionosphere and magnetosphere, J. Atmos. Terr. Phys., 42, 287-298, doi:10.1016/00219169(80)90036-7.

Carlson, H. C., and L. M. Duncan (1977), HF excited instabilities in space plasmas, Radio Sci., 12, 1001-1013, doi:10.1029/RS012i006p01001.

Dhillon, R. S., T. R. Robinson, and T. K. Yeoman (2007), EISCAT Svalbard radar observations of SPEAR-induced $E$ - and $F$ region spectral enhancements in the polar cap ionosphere, Ann. Geophys., 25, 1801-1814, doi:10.5194/angeo-25-1801-2007

Dhillon, R. S., T. R. Robinson, and T. K. Yeoman (2009), Aspect sensitive $E$ - and $F$ region SPEAR enhanced incoherent backscatter observed by the EISCAT Svalbard radar, Ann. Geophys., 27, 65-81, doi:10.5194/angeo27-65-2009.

Djuth, F. T. (1984), HF-enhanced plasma lines in the lower ionosphere, Radio Sci., 19, 383-394, doi:10.1029/RS019i001p00383.

Djuth, F. T., and C. A. Gonzales (1988), Temporal evolution of the HF enhanced plasma line in sporadic E, J. Geophys. Res., 93, 196-208, doi:10.1029/JA093iA01p00196.

Eliasson, B. (2008), Full-scale simulation study of the generation of topside ionospheric turbulence using a generalized Zakharov model, Geophys. Res. Lett., 35, L11104, doi:10.1029/2008GL033866.

Fejer, J. A. (1979), Ionospheric modification and parametric instabilities, Rev. Geophys., 17, 135-153, doi:10.1029/RG017i001p00135.

Fejer, J. A., and E. Leer (1972), Purely growing parametric instability in an inhomogeneous plasma, J. Geophys. Res., 77, 700-708, doi:10.1029/ JA077i004p00700.

Goldman, M. V., D. L. Newman, D. Russell, D. F. DuBois, H. A. Rose, R. P. Drake, and A. M. Rubenchik (1995), Collisional regimes of radiation-driven Langmuir turbulence, Phys. Plasmas, 2(6), 1947-1960, doi:10.1063/1.871455.

Greenwald, R. A., et al. (1995), DARN/SUPERDARN: A global view of the dynamics of high-latitude convection, Space Sci. Rev., 71, 761-796, doi:10.1007/BF00751350.

Hughes, J. M., W. A. Bristow, and R. T. Parris (2004), SuperDARN observations of spectral enhancements excited during an ionospheric heating experiment, Geophys. Res. Lett., 31, L08808, doi:10.1029/2004GL019613.

Isham, B., M. T. Rietveld, T. Hagfors, C. La Hoz, E. Mischin, T. B. Leyser, and A. P. van Eyken (1999), Aspect angle dependence of HF enhanced incoherent backscatter, Adv. Space Res., 24(8), 1003-1006, doi:10.1016/ S0273-1177(99)00555-4.

James, H. G. (1991), Guided Z mode propagation observed in the OEPIPUS A tethered rocket experiment, J. Geophys. Res., 96, 17,865-17,878, doi:10.1029/91JA01650.

Kosch, M. J., E. Mjølhus, M. Ashrafi, M. T. Rietveld, T. Yeoman, and S. Nozawa (2011), Angular dependence of pump-induced bottomside and topside ionospheric plasma turbulence at EISCAT, J. Geophys. Res., 116, A03322, doi:10.1029/2010JA016014.

Lehtinen, M. S., and I. Häggström (1987), A new modulation principle for incoherent scatter measurements, Radio Sci., 22, 625-634, doi:10.1029/ RS022i004p00625.

Leyser, T. B., and A. Y. Wong (2009), Powerful electromagnetic waves for active environmental research in geospace, Rev. Geophys., 47, RG1001, doi:10.1029/2007RG000235.

Mishin, E., T. Hagfors, and B. Isham (2001), A generation mechanism for topside enhanced incoherent backscatter during high frequency modification experiments at Tromsø, Geophys. Res. Lett., 28, 479-482, doi:10.1029/ 2000GL000122.

Mjølhus, E. (1990), On linear conversion in a magnetized plasma, Radio Sci., 25, 1321-1339, doi:10.1029/RS025i006p01321.

Muldrew, D. B. (1978), Langmuir wave propagation and the enhanced plasma line in sporadic E, J. Geophys. Res., 83, 5207-5211, doi:10.1029/JA083iA11 p05207.

Nishikawa, K. (1968), Parametric excitation of coupled waves, II. Parametric plasmon-photon interaction, J. Phys. Soc. Jpn., 24, 1152-1158, doi:10.1143/JPSJ.24.1152.

Rietveld, M. T., B. Isham, T. Grydeland, C. La Hoz, T. B. Leyser, F. Honary, H. Ueda, M. Kosch, and T. Hagfors (2002), HF-pump-induced parametric instabilities in the auroral E region, Adv. Space Res., 29(9), 1363-1368, doi:10.1016/S0273-1177(02)00186-2.

Robinson, T. R. (1989), The heating of the high latitude ionosphere by high power radio waves, Phys. Rep., 179, 79-209, doi:10.1016/0370-1573(89) 90005-7. 
Robinson, T. R. (2002), Effects of multiple scatter on the propagation and absorption of electromagnetic waves in a field-aligned-striated cold magneto-plasma: Implications for ionospheric modification experiments, Ann. Geophys., 20, 41-55, doi:10.5194/angeo-20-41-2002.

Robinson, T. R., T. K. Yeoman, R. S. Dhillon, M. Lester, E. C. Thomas, J. D. Thornhill, D. M. Wright, A. P. van Eyken, and I. W. McCrea (2006), First observations of SPEAR induced artificial backscatter from CUTLASS and the EISCAT Svalbard radars, Ann. Geophys., 24, 291-309, doi:10.5194/ angeo-24-291-2006.

Stubbe, P., and H. Kopka (1980), Modification of the F region by powerful radio waves, in Exploration of the Polar Upper Atmosphere, edited by C. S Deehr and J. A. Holtet, pp. 83-98, D. Reidel, Dordrecht, Netherlands.

Wannberg, G., et al. (1997), The EISCAT Svalbard radar: A case study in modern incoherent scatter radar system design, Radio Sci., 32, 2283-2307, doi:10.1029/97RS01803.

Wright, D. M., et al. (2000), Space Plasma Exploration by Active Radar (SPEAR): An overview of a future facility, Ann. Geophys., 18, 1248-1255, doi:10.1007/s00585-000-1248-7.

Wright, D. M., R. S. Dhillon, T. K. Yeoman, T. P. Robinson, E. C. Thomas, L. J. Baddeley, and S. Imber (2009), Excitation thresholds of fieldaligned irregularities and associated ionospheric hysteresis at very high latitudes observed using SPEAR-induced HF radar backscatter, Ann. Geophys., 27, 2623-2631, doi:10.5194/angeo-27-2623-2009.
Yeoman, T. K., D. M. Wright, and L. J. Baddeley (2006), Ionospheric signatures of ULF waves: Active radar techniques, in Magnetospheric ULF Waves: Synthesis and New Directions, Geophys. Monogr. Ser., vol. 169 edited by K. Takahashi et al., pp. 273-289, AGU, Washington, D.C.

Yeoman, T. K., G. Chisham, L. J. Baddeley, R. S. Dhillon, T. J. T. Karhunen, T. R. Robinson, A. Senior, and D. M. Wright (2008a), Mapping ionospheric backscatter measured by the SuperDARN HF radars-Part 2: Assessing SuperDARN virtual height models, Ann. Geophys., 26, 843-852, doi:10.5194/angeo-26-843-2008.

Yeoman, T. K., L. J. Baddeley, R. S. Dhillon, T. R. Robinson, and D. M. Wright (2008b), Bistatic observations of large and small scale ULF waves in SPEAR-induced HF coherent backscatter, Ann. Geophys., 26, 2253-2263, doi:10.5194/angeo-26-2253-2008.

L. J. Baddeley, University Centre in Svalbard, N-9171 Longyearbyen, Norway. (Lisa.Baddeley@unis.no)

I. Haggstrøm, EISCAT Scientific Association, SE-981 28 Kiruna, Sweden.

M. Rietveld, EISCAT Scientific Association, N-9027 Tromsø, Norway.

T. K. Yeoman, Department of Physics and Astronomy, University of Leicester, Leicester LE1 7RH, UK. 